\title{
Peculiarities of gender identity of deviant adolescents
}

\author{
Daria Belinskaya ${ }^{1, *}$, Elizaveta Goncharova ${ }^{2}$ \\ ${ }^{1}$ Moscow State University of Civil Engineering, 26, Yaroslavskoye Shosse, 109377, Moscow, Russia \\ ${ }^{2}$ Kikot Moscow University of the Ministry of the Interior of Russia, 12, Academician Volgin street, \\ 117437, Moscow, Russia
}

\begin{abstract}
The article is devoted to the study of the formation and manifestation of gender identity in deviant adolescents. The authors analyzed the works devoted to the psychological development of adolescents, taking into account the acceptance or rejection of existing social roles. Special attention is paid to deviant behavior, which partly influences the formation of a person's identity. The authors conducted a study to identify the tendency towards victim behavior in adolescents and correlated them with the data obtained on the definition of character accentuation in students of a regular school and a boarding school. The results of the study confirmed the fact that adolescents with deviant behavior have specific characteristics that make their relationships with their peers and with adults especially difficult. The formation of the gender culture of adolescents takes place on the basis of physical, cognitive development in their relationship with peers and parents, taking into account their psycho-emotional state during puberty.
\end{abstract}

\section{Introduction}

The problem of deviant behavior among adolescents remains a pressing issue, since the presence of one or another deviance can contribute to the formation and development of anti-social personality. Gender identity draws particular attention allowing to analyze data related to the gender development. An adolescent either accepts or rejects social roles and behavioral models, which are offered to them as growing old, what finds reflection in their gender identity.

Adolescence has its own peculiarities of mental development, which are often represented as intrapersonal conflicts. These conflicts include: desire «to be» a grownup comes across with rejection of the value system that adults share; inflated feeling of themself as «the center of the universe», but at the same time they reproach themself; desire to blend into a crowd, but at the same time they seek attention standing out as a flashy individual; attraction to the opposite sex - inability to build relationships[1].

N.V. Zaigraeva claims that gender identity plays the key role in development of personality in adolescence. Parents-children relationships define the success of their socialization[2].

\footnotetext{
*Corresponding author: docent.abrosimova@mail.ru
} 
In the process of gender socialization in childhood, imitation and identification with parents of the same sex are powerful mechanisms. Boys, who are surrounded by female, easily pick up behavior unusual for future men. In girls, emotional and physical isolation from their mother and lack of affection in childhood lead to aberrant rudeness, lack of maternal care and empathy. Thus, a paradoxical situation arises: boys with feminine personality traits are infantile, dependent, with a lack of stamina, determination, strength, and girls are with a high level of masculinity, with immodesty, rudeness and impatience.

V. Kobyletskaya and A. Yachevsky believe that the figure of father plays a curcial role in gender identity. Proper development is possible in the family with both parents. Father becomes a role model for the boy of what a man is; it is also important for the girl to understand what men are [3].

Studies by I. V. Romanov showed that differentiation of masculinity and femininity is more important for boys than for girls. Girls have the ability to combine.

Based on the research of A. Cohen, it can be noted that, since deviant behavior is recognized as such that does not meet social norms and expectations, and they can vary in different societies and at different times, as the concept of «generally accepted norm» is quite relative, and, hence, relative and deviant behavior. Moreover, modern sociology and criminology have developed a strong view of the convention and the construction of deviations[4-6].

Deviant behavior can be viewed from two angles, the first as an act that does not meet norms and expectations; and the second as a social phenomenon expressed in the negation of the foundations of society. Deviant behavior includes crime and other offenses, as well as excessive drinking, alcoholism, drug addiction, suicide, etc. It must be borne in mind that deviancy is inherent in human society, as is conformity (i.e. compliance with the norm).

There are two forms of deviation in science: positive and negative. Therefore «it is fundamentally impossible to «eliminate» all disorganizing, negative deviances (crime, alcoholism, drugs, prostitution, etc.), and keep the positive ones... As it is impossible to «cut» from the magnet one pole, «save» the other (as a result ... there will be two magnets of smaller sizes and each with two poles), or to make the pendulum swing in one side only (the oscillation will fade, the pendulum will stop)» [7-10].

\section{Methods}

In order to analyze the correlation and impact of concepts such as gender identity and adolescent deviation, we conducted a study on the gender differences of adolescents with deviant behavior.

The cohort was 60 boys and girls in the age of 15-17, students from one of the Moscow region school [11] and «Boarding school $\mathrm{N}$ for students with disabilities of the $\mathrm{N}$-th municipal district of the Moscow region»[12].

Methods used:

1. The methodology for the study on the tendency to victim behavior O.O. Andronnikova.

2. G. Shmishek, K. Leongard Invetory.

3. Buss-Durkee Hostility Inventory

\section{Results and discus}

After comparing the results, it was found that level of deviant behavior among boys and girls from «School» is not high, that cannot be said about the respondents from «Boarding School» according to the methodology for «the study on the tendency to victim behavior», 
therefore, only students from «Boarding School» continued the survey.

Table 1. Results of the methodology for the study on the tendency to victim behavior (by O.O. Andronnikova) (\%).

\begin{tabular}{|l|c|c|}
\hline \multicolumn{1}{|c|}{ Scale name } & $\begin{array}{c}\text { Level of tendency to victim } \\
\text { behavior among boys and } \\
\text { girls of «School» }\end{array}$ & $\begin{array}{c}\text { Level of tendency to victim } \\
\text { behavior among boys and girls } \\
\text { of «Boarding School» }\end{array}$ \\
\hline $\begin{array}{l}\text { Social desirability of the } \\
\text { answers }\end{array}$ & 5 & 10 \\
\hline $\begin{array}{l}\text { Tendency to aggressive } \\
\text { victim behavior }\end{array}$ & 3 & 34 \\
\hline $\begin{array}{l}\text { Tendency to self-harming } \\
\text { and self-destructive } \\
\text { behavior }\end{array}$ & 4 & 10 \\
\hline $\begin{array}{l}\text { Tendency to hypersocial } \\
\text { behavior }\end{array}$ & 6 & 5 \\
\hline $\begin{array}{l}\text { Tendency to dependent and } \\
\text { helpless behavior }\end{array}$ & 2 & 10 \\
\hline $\begin{array}{l}\text { Tendency to uncritical } \\
\text { behavior }\end{array}$ & 75 & 16 \\
\hline Realized victimization & 5 & 5 \\
\hline
\end{tabular}

Table 2 presents initial results for G. Shmishek, K. Leongard Inventory among girls of «Boarding School».

Table 2. Initial results for the G. Shmishek, K. Leongard Inventory (girls of «Boarding School»).

\begin{tabular}{|c|c|c|c|c|c|c|c|c|c|c|c|}
\hline \multirow[b]{2}{*}{ № } & \multirow[b]{2}{*}{ Subjects } & \multicolumn{10}{|c|}{ Scales } \\
\hline & & 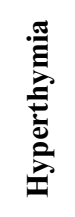 & 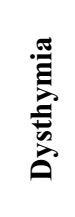 & 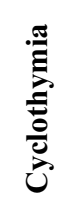 & 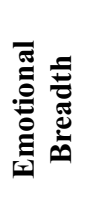 & 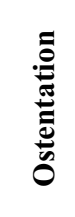 & 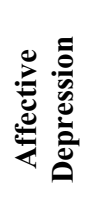 & 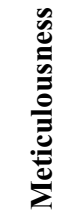 & 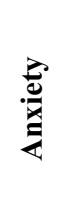 & 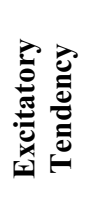 & 节 \\
\hline 1 & U. B. & 21 & 12 & 15 & 21 & 18 & 16 & 12 & 12 & 18 & 18 \\
\hline 2 & I. G. & 12 & 15 & 21 & 18 & 16 & 14 & 22 & 9 & 18 & 12 \\
\hline 3 & A.G. & 15 & 12 & 15 & 9 & 18 & 20 & 12 & 15 & 15 & 24 \\
\hline 4 & S.D. & 21 & 12 & 18 & 15 & 22 & 20 & 8 & 6 & 15 & 24 \\
\hline 5 & T.E. & 18 & 12 & 9 & 12 & 18 & 18 & 12 & 3 & 9 & 12 \\
\hline 6 & M. K. & 15 & 12 & 12 & 18 & 18 & 14 & 16 & 15 & 18 & 12 \\
\hline 7 & T.K. & 15 & 15 & 9 & 18 & 22 & 12 & 18 & 12 & 18 & 18 \\
\hline 8 & V.N. & 12 & 6 & 15 & 9 & 12 & 20 & 14 & 9 & 12 & 18 \\
\hline 9 & O.P. & 18 & 9 & 12 & 12 & 18 & 16 & 8 & 12 & 12 & 24 \\
\hline 10 & A.P. & 9 & 18 & 12 & 15 & 10 & 20 & 12 & 18 & 21 & 24 \\
\hline 11 & A.R. & 9 & 12 & 15 & 18 & 12 & 4 & 8 & 9 & 15 & 24 \\
\hline 12 & T.R. & 15 & 15 & 21 & 9 & 10 & 16 & 14 & 18 & 21 & 18 \\
\hline 13 & M. H. & 12 & 9 & 21 & 15 & 10 & 8 & 10 & 3 & 12 & 24 \\
\hline 14 & Y. Sh. & 24 & 3 & 15 & 27 & 18 & 16 & 12 & 3 & 12 & 18 \\
\hline 15 & I. Sh. & 15 & 9 & 12 & 12 & 14 & 14 & 14 & 21 & 15 & 12 \\
\hline \multicolumn{2}{|c|}{ Mean value } & 15.4 & 11.4 & 14.8 & 15.2 & 15.7 & 15.2 & 12.8 & 11 & 15.4 & 18.8 \\
\hline
\end{tabular}

Initial results of the girls on G. Shmishek, K. Leongard Invenotry show that on scales of 
«Hyperthymia», «Emotional Breadth», «Ostentation», «Affective Depression» and «Excitatory Tendency» the values range from 15.2 to 15.4 points. The highest value of 18.8 points is on a scale of «Exaltation», which is due to the fact that girls tend to reject moral and ethical qualities.

Below are the data obtained from initial results for G. Shmishek, K. Leongard Inventory among boys (table 3 ).

Table 3. Initial results for the G. Shmishek, K. Leongard Inventory (boys of «Boarding School»).

\begin{tabular}{|c|c|c|c|c|c|c|c|c|c|c|c|}
\hline \multirow[b]{2}{*}{ № } & \multirow[b]{2}{*}{ Subjects } & \multicolumn{10}{|c|}{ Scales } \\
\hline & & & 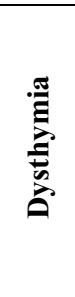 & 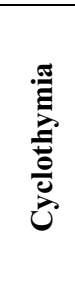 & 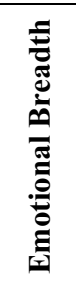 & 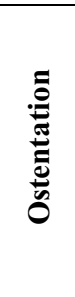 & 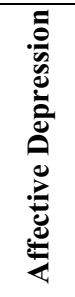 & 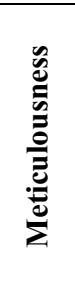 & $\frac{\vec{e}}{\stackrel{e}{x}}$ & 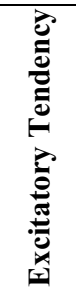 & 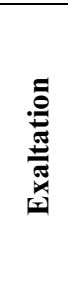 \\
\hline 1 & A.B. & 18 & 16 & 12 & 12 & 18 & 16 & 14 & 9 & 15 & 6 \\
\hline 2 & M. V. & 18 & 12 & 18 & 18 & 12 & 16 & 10 & 12 & 3 & 12 \\
\hline 3 & K. G. & 12 & 12 & 15 & 12 & 14 & 12 & 16 & 3 & 21 & 18 \\
\hline 4 & I. D. & 21 & 6 & 9 & 6 & 18 & 14 & 10 & 12 & 9 & 18 \\
\hline 5 & K. Zh. & 9 & 9 & 15 & 6 & 6 & 12 & 12 & 6 & 3 & 6 \\
\hline 6 & E. K. & 3 & 12 & 12 & 18 & 16 & 14 & 4 & 6 & 12 & 12 \\
\hline 7 & T.K. & 15 & 9 & 9 & 6 & 20 & 16 & 16 & 12 & 6 & 12 \\
\hline 8 & P. K. & 15 & 18 & 6 & 9 & 18 & 18 & 8 & 3 & 15 & 24 \\
\hline 9 & A.K. & 9 & 12 & 12 & 6 & 10 & 8 & 4 & 6 & 12 & 12 \\
\hline 10 & V.K. & 6 & 0 & 9 & 12 & 6 & 14 & 10 & 18 & 18 & 18 \\
\hline 11 & A.M. & 6 & 9 & 12 & 21 & 10 & 14 & 6 & 12 & 6 & 6 \\
\hline 12 & N. M. & 18 & 15 & 15 & 24 & 14 & 10 & 10 & 6 & 9 & 12 \\
\hline 13 & D. P. & 12 & 15 & 9 & 6 & 16 & 12 & 16 & 9 & 9 & 6 \\
\hline 14 & I. S. & 21 & 9 & 9 & 21 & 16 & 20 & 14 & 18 & 14 & 18 \\
\hline 15 & D. H. & 9 & 12 & 15 & 24 & 8 & 18 & 12 & 15 & 12 & 24 \\
\hline & Mean value & 12.8 & 11.1 & 11.8 & 13.4 & 13.5 & 14.3 & 10.8 & 9.8 & 10.9 & 13.6 \\
\hline
\end{tabular}

Initial results for the G. Shmishek, K. Leongard Invenotry show that on scales of «Hyperthymia», «Emotional Breadth», «Ostentation» and «Exaltation» the values range from 12.8 to 13.6 points. The highest value of 14.3 points is on a scale of «Affective Depression», which is due to the fact that boys are more prone to though process disorder.

Analysis of Student's t-test values by G. Shmishek-K. Leongard Inventory is presented in table 4. 
Table 4. Analysis of the significance of difference using Student's t-test values by G. Shmishek-K.

Leongard Inventory.

\begin{tabular}{|c|c|c|c|c|c|c|c|c|c|c|}
\hline \multirow[b]{2}{*}{ Groups } & \multicolumn{10}{|c|}{ Scales } \\
\hline & & 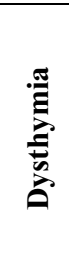 & 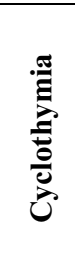 & 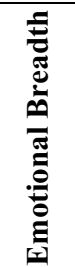 & 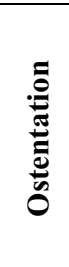 & 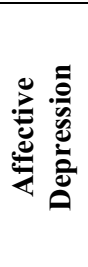 & 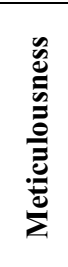 & 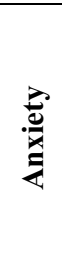 & 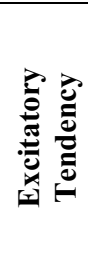 & 氖 \\
\hline Girls & 15.4 & 11.4 & 14.8 & 15.2 & 15.7 & 15.2 & 12.8 & 11 & 15.4 & 18.8 \\
\hline Boys & 12.8 & 11.1 & 11.8 & 13.4 & 13.5 & 14.3 & 10.8 & 9.8 & 10.9 & 13.6 \\
\hline $\begin{array}{c}\text { Student's } \\
\text { t-test }\end{array}$ & 1.4 & 0.2 & $2.3^{*}$ & 0.8 & 1.4 & 0.6 & 1.4 & 0.6 & $2.7^{*}$ & $2.5^{*}$ \\
\hline
\end{tabular}

Designation: $* \mathrm{p} \leq 0,05$.

The table indicates the difference in values of three parameters: cyclothymia, excitatory tendency, exaltation.

Analysis of the results for the G. Shmishek, K. Leongard Inventory of the girls showed that the highest value of 18.8 points is on the «Exaltation» scale.

The striking trait of this type is ability to admire, get amazed. These feelings may often arise for a reason that does not move other people at all: one can be over the moon with a bright spot or give oneself up to despair because of something sad. They are tend to high contact and talkativeness. People of this type often argue, but keep everything out of conflict. They can be drama queens, prone to mood swings, irregular; can go from delight to sadness with a blink of an eye; have psychic lability.

The rest values are lower than the average.

Analysis of the results for the G. Shmishek, K. Leongard Inventory of the boys showed that the highest value of 14.3 points is on the «Affective Depression» scale.

People of modest type demonstrate moderate sociability, nitpicking, susceptibility to moralizing and silent manner. A person of this type often suffers from perceive injustice towards one. Concern and suspiciousness, sensitivity to slights and disappointments, vulnerability and hesitations consequently stem from that.

Analysis of the means of G. Shmishek-K. Leongard Inventory is given in Figure 1.

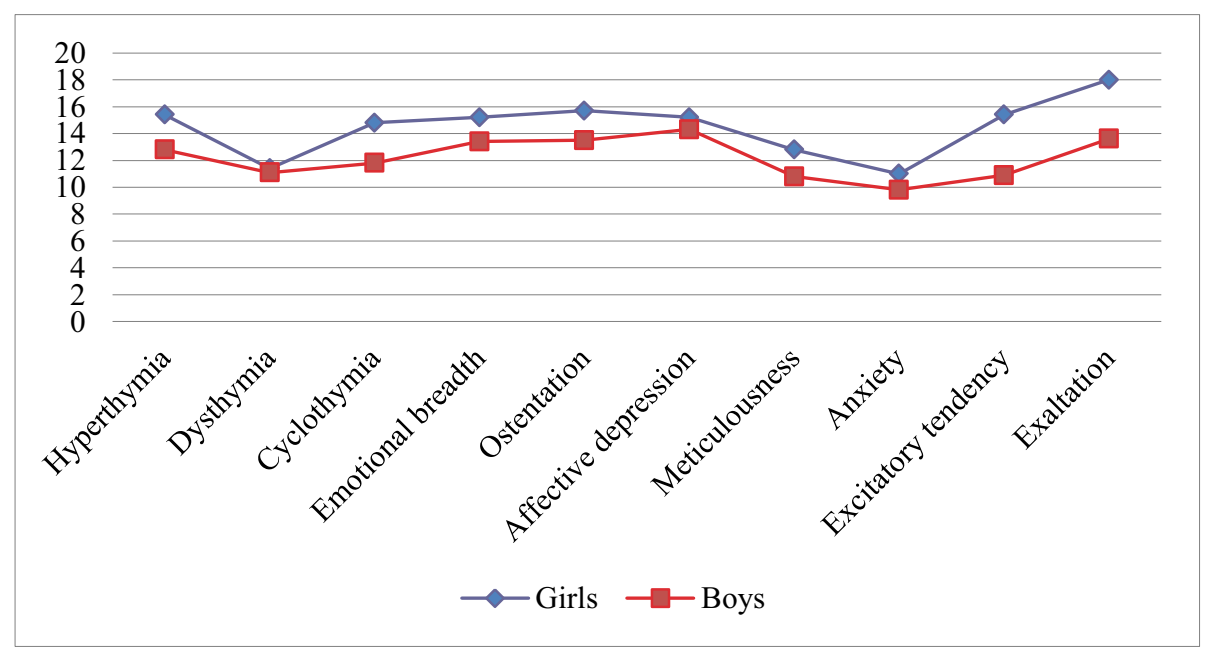

Fig. 1. Analysis of the mean values of G. Shmishek-K. Leongard Inventory. 
The dominant type of accentuated personality is determined by the maximum number of points that the subjects scored on the questionnaire. The number of points indicate the development level of various accentuations of personality traits of children.

Calculation of the significance criterion ( $t$ is Student's test) for the «Cyclothymia» factor (G. Shmishek, K. Leongard Inventory) is presented in table 5.

Table 5. Example of calculation of the significance criterion for «Cyclothymia» (G. Shmishek, K. Leogard Inventory) with Sudent's t-test.

\begin{tabular}{|c|c|c|c|c|c|c|}
\hline \multirow[b]{2}{*}{ № } & \multicolumn{3}{|c|}{ girls } & \multicolumn{3}{|c|}{ boys } \\
\hline & $\stackrel{\mathscr{\Xi}}{\frac{\mathscr{J}}{\sigma}}$ & 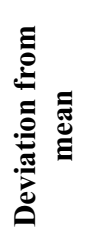 & 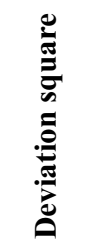 & $\stackrel{\mathscr{E}}{\frac{0}{\pi}}$ & 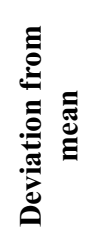 & 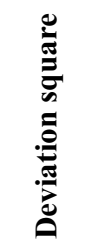 \\
\hline 1 & 15 & 0.2 & 0.04 & 12 & 0.2 & 0.04 \\
\hline 2 & 21 & 6.2 & 38.44 & 18 & 6.2 & 38.44 \\
\hline 3 & 15 & 0.2 & 0.04 & 15 & 3.2 & 10.24 \\
\hline 4 & 18 & 3.2 & 10.24 & 9 & -2.8 & 7.84 \\
\hline 5 & 9 & -5.8 & 33.64 & 15 & 3.2 & 10.24 \\
\hline 6 & 12 & -2.8 & 7.84 & 12 & 0.2 & 0.04 \\
\hline 7 & 9 & -5.8 & 33.64 & 9 & -2.8 & 7.84 \\
\hline 8 & 15 & 0.2 & 0.04 & 6 & -5.8 & 33.64 \\
\hline 9 & 12 & -2.8 & 7.84 & 12 & 0.2 & 0.04 \\
\hline 10 & 12 & -2.8 & 7.84 & 9 & -2.8 & 7.84 \\
\hline 11 & 15 & 0.2 & 0.04 & 12 & 0.2 & 0.04 \\
\hline 12 & 21 & 6.2 & 38.44 & 15 & 3.2 & 10.24 \\
\hline 13 & 21 & 6.2 & 38.44 & 9 & -2.8 & 7.84 \\
\hline 14 & 15 & 0.2 & 0.04 & 9 & -2.8 & 7.84 \\
\hline 15 & 12 & -2.8 & 7.84 & 15 & 3.2 & 10.24 \\
\hline Total & 222 & -0 & 224.4 & 177 & -0 & 152.4 \\
\hline
\end{tabular}

$t_{\text {Emp }}=2.3$.

Next let us consider $\mathrm{t}_{\mathrm{cr}}$ for $\mathrm{P} \leq 0.01$ and $\mathrm{P} \leq 0.05$, and draw significance axis after.

\begin{tabular}{|c|c|}
\hline \multicolumn{2}{|c|}{$\mathrm{t}_{\mathrm{cr}}$} \\
\hline $\mathrm{P} \leq 0.05$ & $\mathrm{P} \leq 0.01$ \\
\hline 2.05 & 2.76
\end{tabular}

Significance axis:

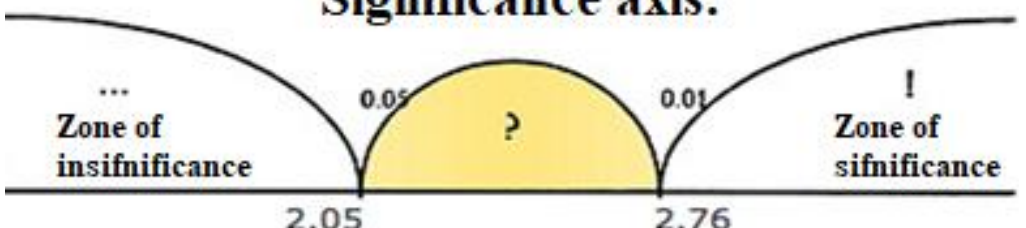

Fig. 2. Critical values.

Our empirical value of $t$ (2.3) lies in the area of uncertainty.

Therefore, the following can be said, analyzing table 2, that the difference between boys and girls with deviant behavior, according to accentuations of personality traits: 
cyclothymia ( $\mathrm{T}_{\mathrm{E}}$ 2.3); excitatory tendency $\left(\mathrm{T}_{\mathrm{E}} 2.7\right)$; exaltation $\left(\mathrm{T}_{\mathrm{E}} 2.5\right)$ - are small comparing with tendency to significance, since $\mathrm{T}_{\mathrm{E}}>\mathrm{T}_{\mathrm{cr}}$ when $(\mathrm{p}=0.05)$. 6.

Initial results for the Buss-Durkee Hostility Inventory among girls are presented in table

Table 6. Initial results for the Buss-Durkee Hostility Inventory (girls of «Boarding School»).

\begin{tabular}{|c|c|c|c|c|c|c|c|c|c|c|c|}
\hline \multirow[b]{2}{*}{ № } & \multirow[b]{2}{*}{ Subjects } & \multicolumn{10}{|c|}{ Scales } \\
\hline & & 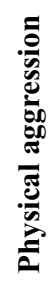 & 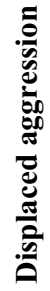 & & 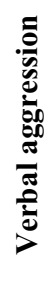 & 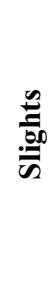 & 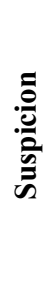 & 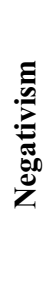 & 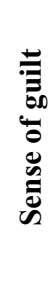 & 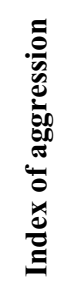 & 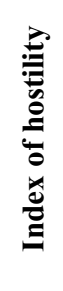 \\
\hline 1 & U. B. & 3 & 6 & 9 & 4 & 7 & 4 & 3 & 8 & 22 & 11 \\
\hline 2 & I. G. & 6 & 4 & 7 & 7 & 6 & 8 & 4 & 7 & 24 & 14 \\
\hline 3 & A.G. & 9 & 7 & 9 & 9 & 6 & 5 & 4 & 9 & 34 & 11 \\
\hline 4 & S.D. & 9 & 9 & 8 & 11 & 7 & 8 & 4 & 9 & 34 & 15 \\
\hline 5 & T.E. & 4 & 5 & 9 & 12 & 6 & 8 & 4 & 8 & 30 & 14 \\
\hline 6 & M. K. & 4 & 5 & 6 & 8 & 4 & 7 & 2 & 5 & 23 & 11 \\
\hline 7 & T.K. & 5 & 2 & 5 & 12 & 5 & 5 & 4 & 7 & 24 & 10 \\
\hline 8 & V.N. & 8 & 8 & 7 & 7 & 7 & 6 & 4 & 7 & 30 & 13 \\
\hline 9 & O. P. & 7 & 5 & 4 & 9 & 7 & 6 & 2 & 6 & 25 & 13 \\
\hline 10 & A.P. & 9 & 6 & 9 & 12 & 7 & 6 & 5 & 8 & 30 & 13 \\
\hline 11 & A.R. & 2 & 3 & 2 & 4 & 4 & 7 & 2 & 8 & 8 & 11 \\
\hline 12 & T.R. & 6 & 6 & 8 & 9 & 5 & 9 & 2 & 8 & 23 & 14 \\
\hline 13 & M. H. & 4 & 6 & 4 & 9 & 5 & 10 & 4 & 8 & 17 & 15 \\
\hline 14 & Y. Sh. & 5 & 5 & 4 & 9 & 7 & 9 & 4 & 9 & 18 & 16 \\
\hline 15 & I. Sh. & 3 & 3 & 7 & 10 & 4 & 4 & 4 & 6 & 23 & 8 \\
\hline & Mean value & 5.6 & 5.3 & 6.5 & 8.8 & 5.8 & 6. & 3.5 & 7.5 & 24.3 & 12.6 \\
\hline
\end{tabular}

The obtained results allow us to point out higher values among girls on the following scales: irritation (6.5), verbal aggression (8.8), suspicion (6.8), sense of guilt (7.5). The overall index of aggression of the girls is 24.3 , and 12.6 is for the index of hostility. 7.

Initial results for the Buss-Durkee Hostility Inventory among boys are presented in table 
Table 7. Initial results for the Buss-Durkee Hostility Inventory (boys of «Boarding School»).

\begin{tabular}{|c|c|c|c|c|c|c|c|c|c|c|c|}
\hline \multirow[b]{2}{*}{ № } & \multirow[b]{2}{*}{ Subjects } & \multicolumn{10}{|c|}{ Scales } \\
\hline & & 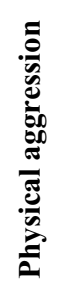 & 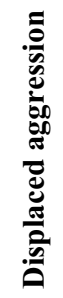 & : & 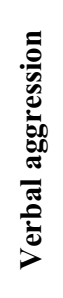 & 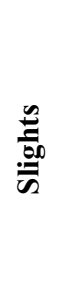 & 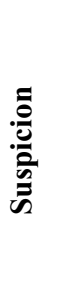 & 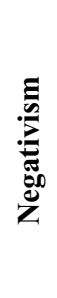 & 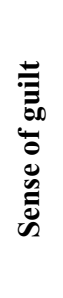 & 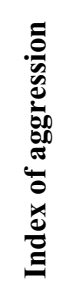 & 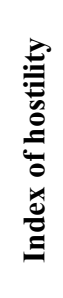 \\
\hline 1 & A.B. & 4 & 3 & 3 & 5 & 4 & 3 & 2 & 3 & 15 & 7 \\
\hline 2 & M. V. & 9 & 5 & 8 & 8 & 4 & 5 & 3 & 6 & 30 & 9 \\
\hline 3 & K. G. & 9 & 8 & 10 & 8 & 7 & 8 & 5 & 9 & 35 & 15 \\
\hline 4 & I. D. & 6 & 7 & 2 & 8 & 4 & 4 & 4 & 5 & 23 & 8 \\
\hline 5 & K. Zh. & 6 & 3 & 3 & 5 & 5 & 4 & 2 & 5 & 14 & 9 \\
\hline 6 & E. K. & 9 & 7 & 7 & 10 & 5 & 8 & 4 & 5 & 33 & 13 \\
\hline 7 & T.K. & 8 & 4 & 5 & 11 & 6 & 6 & 4 & 3 & 28 & 12 \\
\hline 8 & P. K. & 3 & 5 & 4 & 2 & 2 & 5 & 3 & 6 & 14 & 7 \\
\hline 9 & A.K. & 10 & 7 & 9 & 10 & 4 & 5 & 3 & 5 & 36 & 9 \\
\hline 10 & V.K. & 9 & 6 & 8 & 4 & 7 & 5 & 1 & 4 & 21 & 12 \\
\hline 11 & A.M. & 9 & 7 & 8 & 7 & 7 & 8 & 4 & 9 & 24 & 15 \\
\hline 12 & N. M. & 5 & 2 & 4 & 6 & 3 & 3 & 1 & 5 & 15 & 6 \\
\hline 13 & D. P. & 9 & 3 & 9 & 11 & 7 & 7 & 3 & 5 & 32 & 14 \\
\hline 14 & I. S. & 4 & 6 & 8 & 5 & 6 & 5 & 0 & 8 & 17 & 11 \\
\hline 15 & D. H. & 6 & 1 & 5 & 8 & 6 & 5 & 4 & 9 & 19 & 11 \\
\hline & Mean value & 7.1 & 4.9 & 6.2 & 7.2 & 5.1 & 5.4 & 2.9 & 5.8 & 23.7 & 10.5 \\
\hline
\end{tabular}

The obtained results allow us to point out higher values among boys on the following scales: physical aggression (7.1), verbal aggression (7.2).

The overall index of aggression of the boys is 23.7 , and 10.5 is for the index of hostility. The data demonstrate that the overall index of aggression of the boys is lower by 0.6 points than the one of girls, whereas index of hostility is lower by 2.1 points.

Analysis of the significance of difference using Student's t-test values by Buss-Durkee Hostility Inventory is presented in table 8. 
Table 8. Analysis of the significance of difference using Student's t-test values by Buss-Durkee Hostility Inventory.

\begin{tabular}{|c|c|c|c|c|c|c|c|c|c|c|}
\hline \multirow[b]{2}{*}{ Groups } & \multicolumn{10}{|c|}{ Scales } \\
\hline & 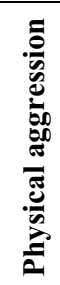 & 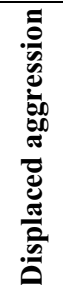 & : & 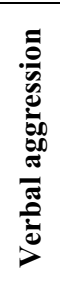 & $\begin{array}{l}\stackrel{\mathscr{E}}{00} \\
\stackrel{0}{\sigma}\end{array}$ & 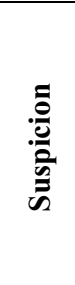 & 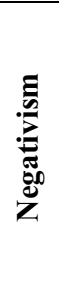 & 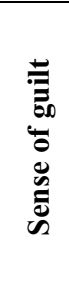 & 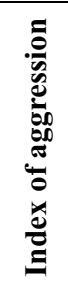 & 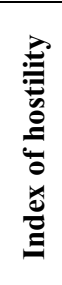 \\
\hline Girls & 5.6 & 5.3 & 6.5 & 8.8 & 5.8 & 6.8 & 3.5 & 7.5 & 24.3 & 12.6 \\
\hline Boys & 7.1 & 4.9 & 6.2 & 7.2 & 5.1 & 5.4 & 2.9 & 5.8 & 23.7 & 10.5 \\
\hline $\begin{array}{c}\text { Student's t- } \\
\text { test }\end{array}$ & 1.7 & 0.5 & 0.4 & 1.7 & 1.3 & $2.2^{*}$ & 1.4 & $2.9^{*}$ & 0.2 & $2.2 *$ \\
\hline
\end{tabular}

Designation: * $-\mathrm{p} \leq 0,05$.

Table 8 shows the difference only in three indicators, which relate to hostility and aggression: girls demonstrate higher levels of suspicion, sense of guilt and the index of hostility than boys.

Therefore, the following can be said, analyzing the table that the difference between boys and girls with deviant behavior, on the scales of: suspicion $\left(\mathrm{T}_{\mathrm{E}} 2.2\right)$; sense of guilt $\left(\mathrm{T}_{\mathrm{E}}\right.$ $2.9)$; index of aggression ( $\left.\mathrm{T}_{\mathrm{E}} 2.2\right)$ - are small comparing with tendency to significance, since $\mathrm{T}_{\mathrm{E}}>\mathrm{T}_{\mathrm{cr}}$ when $(\mathrm{p}=0.05)$.

\section{Conclusions}

To sum up, boarding school children are more exposed to negative phenomena such as drug addiction, alcoholism and prostitution. So, empirical research has shown that gender differences in deviant adolescents manifest themselves in meaningful distinctions between individual traits (cyclothymia, excitatory tendency, exaltation, aggressiveness, suspicion, sense of guilt, hostility index).

Adolescents with deviant behavior have peculiarities that complicate their relationships with peers and adults. Hence, further negative attitude and wrong communication contribute to how their development [8]will go.

Adolescent culture of gender is a complex concept. It encompasses gender role, gender identity, gender stereotypes, gender socialization. In particular, it is impossible to imagine the establishment of a gender culture among adolescents without considering their physical and cognitive development, omitting their relationships with peers and parents, and leaving their psychological and emotional state during puberty[9].

It is advisable, through sociometric methods, to constantly monitor the dynamics of interpersonal relations, to know and develop the self-esteem of adolescents with deviant behavior through the evaluation of their activities and relationships.

\section{References}

1. B.V. Zeigarnik, Psychology of Personality: Norm and Pathology (M., Voronezh, 2018)

2. E. Baust, On the Reasons Defining Male and Female Offspring (Kiev, 1872)

3. T.L. Bessonova, Psychological features of the sex-role self-awareness and selfacceptance of the personality of adolescents: Abstract. PhD thesis in psychology (M., 1994) 
4. Y. Gilinsky, V. Afanasiev, Sociology of deviant behavior (SPb, 1993)

5. E.M. Goncharova, Bulletin of the Moscow University of the Ministry of Internal Affairs of Russia 4, 221-224 (2017)

6. B.V. Zeigarnik, Psychology of Personality: Norm and Pathology (M., Voronezh, 2018)

7. A.Y. Nagornova, M.R. Arpent'yeva, M.A. Vinichenko, et al, Psychology of relationships in the context of personality development. Multi-authored monograph (Ulyanovsk, 2017)

8. S. Caffrey, C. Mundy, The Sociology of Crime and Deviance: Selected Issues (Greenwich University Press, 1995)

9. S. Barkan, Criminology. A Sociological Understanding (Prentice Hall, 1997) 